\title{
The Terracol and Ardouin developmental model of frontal sinus drainage pathway and surrounding spaces: a radiologic validation
}

\author{
Marco Ferrari, MD1 iD , Alberto Schreiber, MD¹, Davide Mattavelli, MD¹, Vittorio Rampinelli, MD²,
} Barbara Buffoli, PhD², Marco Ravanelli, MD ${ }^{3}$, Matteo Bettinsoli ${ }^{2}$, Luigi F. Rodella, MD, MSc ${ }^{2}$ and Piero Nicolai, MD ${ }^{1}$

Background: The complexity of the frontal sinus drainage pathway (FSDP) can be challenging even for expert surgeons. Several classifications have been proposed to simplify the understanding of FSDP, whose anatomical variability can be simplified based on the knowledge of its developmental mechanisms.

Methods: Cone-beam computed tomography studies performed at the Unit of Radiology of the University of Brescia between March and November 2012 were retrospectively analyzed. FSDP was classified as medial or lateral to the vertical portion of the uncinate process and the following anatomical variants were studied: agger nasi cell, Kuhn's cells, suprabullar cell, supraorbital ethmoid cell, suprabullar frontal cell, and frontal septal cell. The developmental model of the FSDP proposed by Terracol and Ardouin was analyzed and expected associations between the position of the drainage pathway and anatomical variants were formulated. Statistical associations between anatomical variants and the position of FSDP were calculated and compared with expected associations to validate the developmental model.

Results: The anatomical variants of FSDP statistically validated the developmental model of Terracol and Ardouin.

Conclusion: Knowledge of the possible developmental patterns of FSDP helps the surgeon in the understanding of the complexity of the frontoethmoidal region. (C) 2017 ARSAAOA, LLC.

Key Words:

FESS; frontal sinusotomy; sinus anatomy; paranasal sinuses; development of the paranasal sinuses

How to Cite this Article:

Ferrari M, Schreiber A, Mattavelli D, et al. The Terracol and Ardouin developmental model of frontal sinus drainage pathway and surrounding spaces: a radiologic validation. Int Forum Allergy Rhinol. 2017;XX:1-7.
I $\mathrm{n}$ the attempt to simplify the anatomical complexity of the frontoethmoidal area, several classifications were developed, ${ }^{1-3}$ and a surgical-oriented classification of air spaces surrounding the frontal sinus drainage pathway (FSDP) was recently published by our group. ${ }^{4}$ Moreover,

\footnotetext{
${ }^{1}$ Unit of Otorhinolaryngology-Head and Neck Surgery, Department of Surgical Specialties, Radiological Sciences, and Public Health, University of Brescia, Brescia, Italy; ${ }^{2}$ Section of Anatomy and Physiopathology, Department of Clinical and Experimental Sciences, University of Brescia, Brescia, Italy; ${ }^{3}$ Unit of Radiology, Department of Surgical Specialties, Radiological Sciences, and Public Health, University of Brescia, Brescia, Italy

Correspondence to: Marco Ferrari, MD, Unit of Otorhinolaryngology-Head and Neck Surgery, Department of Medical and Surgical Specialties, Radiological Sciences, and Public Health, University of Brescia, Largo Spedali Civili, 1, 25123 Brescia, Italy; e-mail: 1990marcoferrari@gmail.com

Potential conflict of interest: None provided.

Received: 9 November 2017; Accepted: 19 November 2017

DOI: $10.1002 / a l r .22063$

View this article online at wileyonlinelibrary.com.
}

the nomenclature of the frontoethmoidal anatomy has been recently revised in the International Frontal Sinus Anatomy Classification (IFAC). ${ }^{5}$ Despite these important refinements, the anatomy of FSDP and frontal recess remains tricky to learn and its variability can make the preoperative analysis of patient imaging challenging also for expert surgeons.

The anatomical variability of FSDP and surrounding spaces can be simplified based on the knowledge of the developmental mechanism of the frontal recess. The frontal sinus develops from the 13 th week of intrauterine life up to the age of twenty as a result of the progressive pneumatization of the frontal bone. ${ }^{6,7}$ Nevertheless, only a few studies focused on the development of FSDP and related air spaces within the frontoethmoidal area. According to Terracol and Ardouin, ${ }^{8}$ as reported by Terrier et al., ${ }^{9}$ before the frontal sinus develops, 3 groups of "primordial" cells ( 2 anterior and 1 posterior) form the upper portion of the anterior ethmoid: 
- Orbital cells, which are located between the uncinate process (UP) medially and the medial orbital wall laterally;

- Nasal cells, which are placed between the middle turbinate medially and the UP laterally;

- Bullar cells, which are between the anterior wall of the ethmoidal bulla anteriorly and the basal lamella of the middle turbinate posteriorly.

The frontal sinus develops from 1 of these 3 groups of cells and the FSDP subsequently acquires two possible spatial relationships (ie, medial or lateral) with the so-called "suprainfundibular plate," 1 of the vertical insertions of the UP that joins the anterior wall of the ethmoidal bulla (Fig. 1). ${ }^{10,11}$ Meanwhile, primordial cells, which do not give rise to the frontal sinus, make up the frontoethmoidal air spaces surrounding the FSDP. As a consequence, specific anatomical variants of the frontal recess and FSDP could be distinctive of a specific origin (ie, nasal, orbital, or bullar) of the frontal sinus.

The aim of this study was to validate Terracol and Ardouin's developmental model of the frontal sinus in view of our anatomical-radiologic observations, by studying statistical associations between the location of FSDP and frontoethmoidal anatomical variants. This model could be an additional way to better understand the frontal recess and FSDP anatomy and provide a simplified anatomical classification of the wide gamut of frontoethmoidal variants.

\section{Patients and methods}

All patients who underwent cone beam computed tomography (CBCT) (NewTom 5G; QR Srl, Verona, Italy) at the Unit of Radiology of the University of Brescia between March and November 2012 were retrospectively reviewed. In all cases, the radiological examination was obtained for neurologic, ocular, or sinus symptoms. The following exclusion criteria were applied: age less than 18 years, massive polyposis, craniofacial malformations or trauma, tumors involving the sinonasal tract, and previous surgery. Imagepackages were anonymized with image-analysis software (Osirix ${ }^{\circledR}$; Pixmeo SARL, Switzerland).

\section{Anatomical study}

A multiplanar reconstruction for all CBCT was obtained for anatomical study. According to the agger-bullar classification $(\mathrm{ABC}),{ }^{4}$ the FSDP was classified as medial or lateral with respect to the upper insertion of the UP. The following anatomical variants of the modified Bent and Kuhn classification, ${ }^{1}$ updated according to the IFAC, ${ }^{5}$ were searched for:

- Agger nasi cell (ANC): defined as the most anterior cell that could be seen in a coronal section, anterior to the middle turbinate insertion. To simplify the statistical analysis, lacrimal cells and genuine agger nasi cells were grouped together, although they are different variants of pneumatization of the inferolateral portion of the anterior ethmoid. ${ }^{12}$ The terminal recess, defined as the anterosuperior portion of the infundibulum ethmoidale (ethmoid infundibulum) without the sphere-like shape of a cell, was separately classified. When the terminal recess was not associated with ANC it was defined as "isolated terminal recess."

- Kuhn's cells (also known as "frontoethmoidal cells"): a group of cells lying close to or within the frontal process of the maxillary bone and above the ANC. They were further classified as follows:

oType 1: a single cell not protruding into the frontal sinus.

oType 2: more than 1 cell not protruding into the frontal sinus.

oType 3: at least 1 cell protruding into the frontal sinus for less than half of its craniocaudal extension.

oType 4: at least one cell protruding into the frontal sinus for more than half of its craniocaudal extension.

As recently reported in the IFAC, ${ }^{5}$ type 1 and 2 Kuhn's cells have been grouped as "supra-agger cells" (SAC), type 3 and 4 as "supra-agger frontal cells" (SAFC). From here onwards, SA(F)C means "SAC or SAFC".

- Suprabullar cell (SBC): a cell that lies over the most inferior air space pneumatizing the ethmoidal bulla, and not protruding into either the frontal sinus or orbital roof. SBCs extending into the orbital roof and those protruding into the frontal sinus were called supraorbital ethmoidal cells (SOECs) and suprabullar frontal cells (SBFCs), respectively. From here onwards, $\mathrm{SB}(\mathrm{F}) \mathrm{C}$ means "SBC or SBFC".

- Frontal septal cell (FSC): a cell resulting from pneumatization of the interfrontal sinus septum draining into either the anterior ethmoid or the frontal sinus. Previously known as "interfrontal sinus septal cell."

- Concha bullosa (CB): a cell or recess resulting from pneumatization of the bulbous portion of the middle turbinate.

\section{Statistical analysis}

Prevalence of each anatomical variant was calculated with 95\% confidence interval (CI). Statistical associations between coupled anatomical variants were investigated by the chi-square test or Fisher's exact test, as appropriate. Level of significance was set at 0.05 , trend of significance was considered for $p$ value between 0.05 and 0.10 .

\section{Developmental model}

According to Terracol and Ardouin's model, ${ }^{8,9}$ expected associations between the position of FSDP (medial or lateral) and frontoethmoidal anatomical variants were inferred a priori (Table 1):

- FSDP developing from nasal cell is medial to UP, and should be consequently associated with the presence of $\mathrm{ANC} / \mathrm{SA}(\mathrm{F}) \mathrm{C}$ and $\mathrm{SB}(\mathrm{F}) \mathrm{C}$, arising from orbital and bullar cells, respectively. 

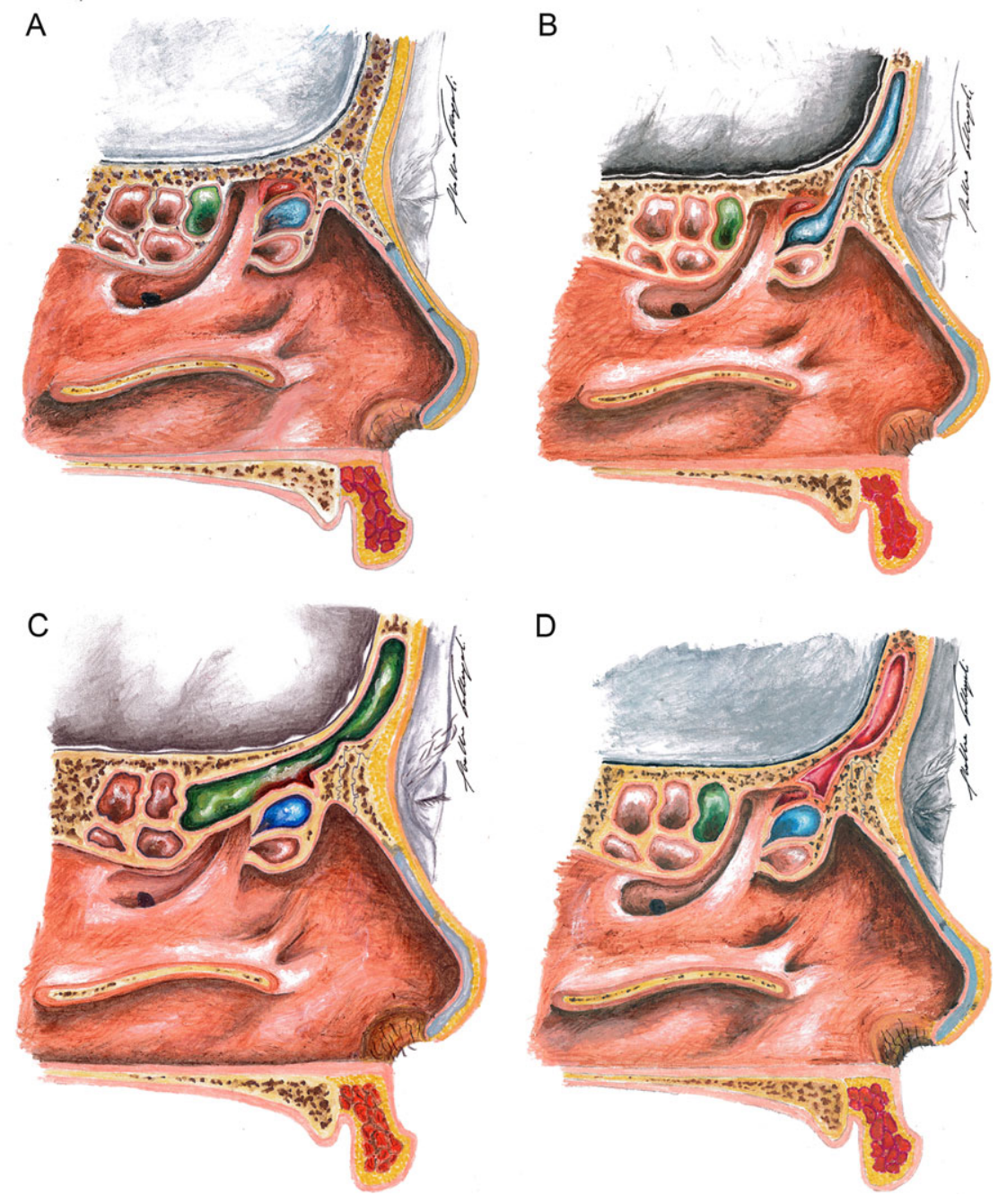

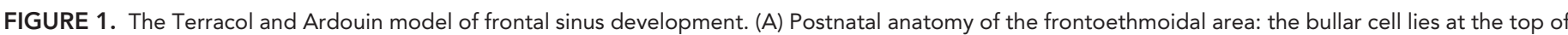

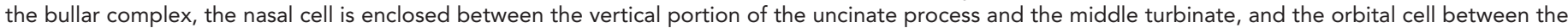

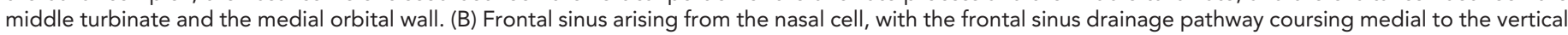

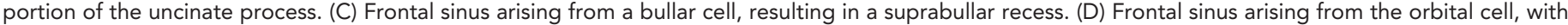
the drainage pathway being lateral to the vertical portion of the uncinate process.

TABLE 1. Expected associations between the position of the frontal sinus drainage pathway and frontoethmoidal anatomical variants, according to Terracol and Ardouin's model of development of the frontal sinus

\begin{tabular}{|l|c|c|c|c|c|c|c|}
\hline Drainage pathway & gANC/LC & SA(F)C & SB(F)C & SOEC & iTR & SBR & FSC \\
\hline Medial & + & + & $?$ & $?$ & - & $?$ & - \\
Lateral & - & - & $?$ & $?$ & + & $?$ & + \\
\hline
\end{tabular}

"+" = significant positive association; "-" = significant negative association "?" = association not inferable from the developmental model; FSC = frontal septal cell; gANC/LC = genuine agger nasi cell and lacrimal cell; iTR $=$ isolated terminal recess; $\mathrm{SA}(\mathrm{F}) \mathrm{C}=$ supra-agger (frontal) cell; $\mathrm{SB}(\mathrm{F}) \mathrm{C}=$ suprabullar (frontal) cell; SBR = suprabullar recess; SOEC = supraorbital ethmoidal cell.

- FSDP arising from orbital cells is lateral to UP, and should be associated with the presence of FSC and $\mathrm{SB}(\mathrm{F}) \mathrm{C}$ stemming from nasal and bullar cells, respectively.
Furthermore, an isolated terminal recess of the ethmoidal infundibulum (without $\mathrm{ANC} / \mathrm{SA}(\mathrm{F}) \mathrm{C}$ ) could also be expected.

- FSDP arising from bullar cells is more difficult to predict because the cells can grow either close to the middle turbinate or along the medial orbital wall, thus medial or lateral to the UP, respectively. This setting can be recognized due to the presence of a suprabullar recess, which is the path followed by the bullar cell when extending into the frontal bone. Furthermore, in this scenario a $\mathrm{SB}(\mathrm{F}) \mathrm{C}$ should not be expected, because it is hypothetically a remnant of a bullar cell not generating the frontal sinus.

Significant associations identified with the statistical analysis were checked to be consistent with expected associations according to the developmental model reported by Terracol and Ardouin. 8,9 
TABLE 2. Summary of prevalence values of frontoethmoidal anatomical variants

\begin{tabular}{|l|c|c|}
\hline Anatomical variants & Prevalence (\%) & Cl (\%) \\
\hline gANC/LC & 92.1 & $87.2-97.1$ \\
iTR & 7.9 & $3.0-12.9$ \\
K1 & 33.3 & $24.7-42.0$ \\
K2 & 14.9 & $8.4-21.5$ \\
K3 & 12.3 & $6.3-18.3$ \\
K4 & 0 & N.A. \\
SAC & 47.4 & $38.2-56.3$ \\
SAFC & 12.3 & $6.3-18.3$ \\
SBC & 80.7 & $73.5-88.0$ \\
SOEC & 54.4 & $45.3-63.7$ \\
SBFC & 22.8 & $15.1-30.5$ \\
eFSC & 13.2 & $7.0-19.4$ \\
fFSC & 9.7 & $4.2-15.1$ \\
CB & 17.5 & $10.6-24.5$ \\
SBR & 9.7 & $4.2-15.1$ \\
m & 63.2 & $54.3-72.0$ \\
I & 36.8 & $28.0-45.7$ \\
\hline
\end{tabular}

$\mathrm{CB}=$ concha bullosa; $\mathrm{Cl}=$ confidence interval; $\mathrm{eFSC}=$ frontal septal cell arising from the frontoethmoidal area; $\mathrm{FFSC}=$ frontal septal cell arising from the frontal sinus; $\mathrm{gANC}=$ genuine agger nasi cell (cumulated with LC); iTR $=$ isolated terminal recess (the sum of prevalence values of gANC, LC, and TR is $100 \%$ ); K1-4 = type 1 to 4 Kuhn's cells; I = frontal sinus drainage pathway lying lateral to the upper insertion of the uncinate process; $L C=$ lacrimal cell; $\mathrm{m}=$ frontal sinus drainage pathway lying medial to the upper insertion of the uncinate process; N.A. $=$ not available; $\mathrm{SAC}=$ supra-agger cell; SAFC $=$ supra-agger frontal cell; $\mathrm{SBC}=$ suprabullar cell; $\mathrm{SBFC}=$ suprabullar frontal cell; $\mathrm{SBR}=$ suprabullar recess; $\mathrm{SOEC}=$ supraorbital ethmoidal cell; $\mathrm{TR}=$ terminal recess.

\section{Results}

A total of 57 CBCT were included in the study. The prevalence of the anatomical variants detected is summarized in Table 2 .

\section{Associations with medial FSDP}

The FSDP was medial to the UP upper insertion in $63.2 \%$ (95\% CI, 54.3 to $72.0 \%$ ) of cases.

The medial FSDP was significantly associated to the presence of SA(F)C $(p<0.0001)$.

An SBFC was identified in $29.2 \%$ and $11.9 \%$ of patients with medial and lateral FSDP, respectively. This association was statistically significant $(p=0.034)$.

The ANC was absent in $2.8 \%$ and $16.7 \%$ of patients with medial and lateral FSDP, respectively. This different incidence was statistically significant $(p=0.008)$.
TABLE 3. Summary of anatomical variants associated with medial or lateral frontal sinus drainage pathway with the respect to the suprainfundibular plate

\begin{tabular}{|l|c|c|c|c|c|c|c|}
\hline Drainage pathway & gANC/LC & SA(F)C & SBFC & SOEC & iTR & SBR & FSC \\
\hline Medial & + & + & + & $\mathrm{a}$ & - & - & - \\
Lateral & - & - & - & $\mathrm{a}$ & + & + & + \\
\hline
\end{tabular}

"+" = significant positive association; "-" = significant negative association; "a" = absence of significant association; FSC = frontal septal cell; gANC/LC = genuine agger nasi cell and lacrimal cell; iTR = isolated terminal recess; SA(F)C = supra-agger (frontal) cell; SBFC = suprabullar frontal cell; SBR = suprabullar recess; $\mathrm{SOEC}=$ supraorbital ethmoidal cell

\section{Associations with lateral FSDP}

The FSDP was lateral to the UP upper insertion in $36.8 \%$ (95\% CI, 28.0 to $45.7 \%$ ) of cases.

The lateral FSDP was significantly associated to the absence of SA(F)C $(p<0.0001)$.

A suprabullar recess was identified in $4.2 \%$ and $19.1 \%$ of patients with medial and lateral FSDP, respectively. This association was statistically significant $(p=0.018)$.

An FSC arising from the frontoethmoidal area was identified in $5.6 \%$ and $26.2 \%$ of patients with medial and lateral FSDP, respectively. This association was statistically significant $(p=0.003)$.

\section{Further associations}

The SBC and suprabullar recess were found to be usually mutually exclusive $(p<0.0001)$, with only $2.6 \%$ of cases of concomitant presence of both variants.

Although SBFC was never present with a suprabullar recess, this association showed only a trend of significance $(p=0.066)$.

All expected associations consistent with Terracol and Ardouin's developmental model of the frontal sinus have been confirmed (Table 1 and 3 ).

\section{Discussion}

The results of the present study corroborate the developmental model proposed by Terracol and Ardouin, as all the statistical associations between anatomical variants are in agreement with the hypothesis that the frontal sinus takes origin from 1 of the 3 groups of primordial cells (ie, orbital, nasal, or bullar cell). ${ }^{8,9}$ In this model, the entity and hierarchical order of primordial cells growth determines the frontoethmoidal anatomy. In particular, the position of the primordial cell forming the frontal sinus defines the relationships between the FSDP and the surrounding anatomical structures.

The frontoethmoidal region represents the crossroads between frontal, ethmoid, lacrimal, and maxillary bone. During the embryogenesis, this area pneumatizes starting from the sulci between ethmoturbinals of lateral nasal wall. The pneumatization process is defined "intramural" until confined to the ethmoid bone and "extramural" 

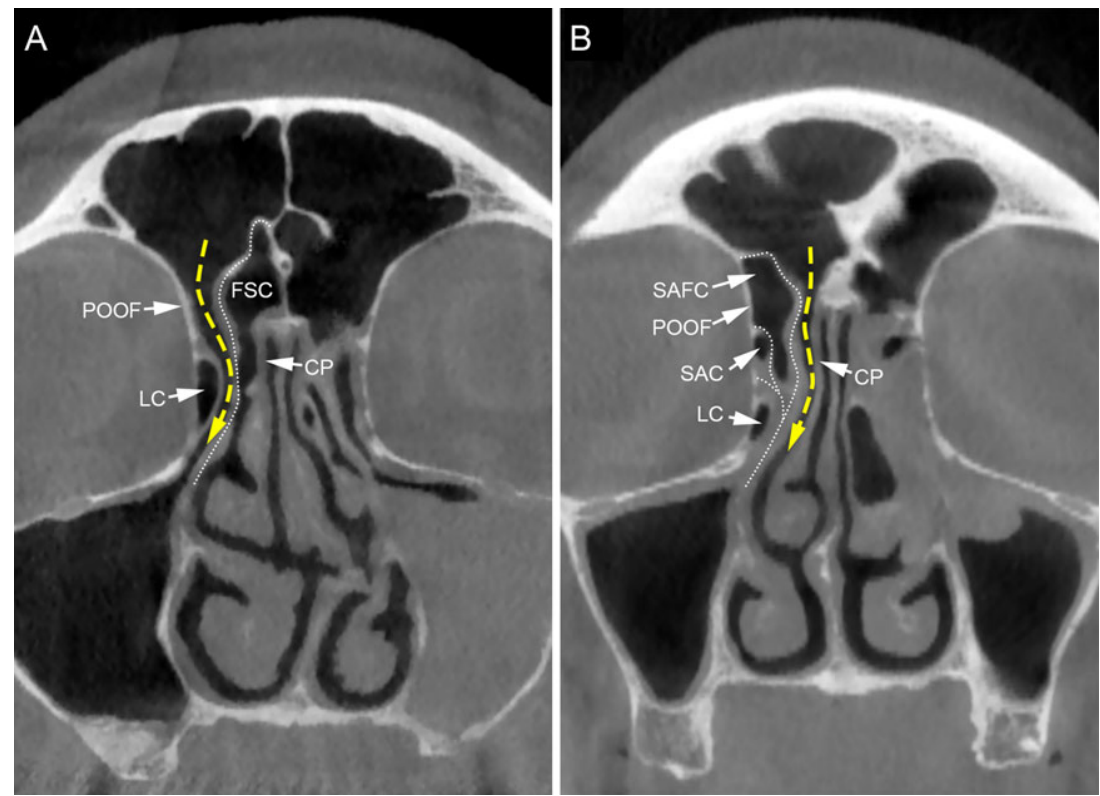

FIGURE 2. The FSC and SAFC. (A) Paracoronal reconstruction showing an FSC arising from the frontoethmoidal area. The bony boundaries of the cell are made up by the superior portion of the uncinate process (white dotted line). The frontal sinus drainage pathway (yellow dashed arrow) lies lateral to the uncinate process. (B) Paracoronal reconstruction showing an SAFC. Several bony insertion of the uncinate process make up the boundaries of the LC and SAC. $\mathrm{CP}=$ Conchal plate; $\mathrm{FSC}=$ frontal septal cell; $\mathrm{LC}=$ lacrimal cell; $\mathrm{POOF}=$ Pars orbitalis ossis frontalis; $\mathrm{SAC}=$ supra-agger cell; $\mathrm{SAFC}=$ supra-agger frontal cell.
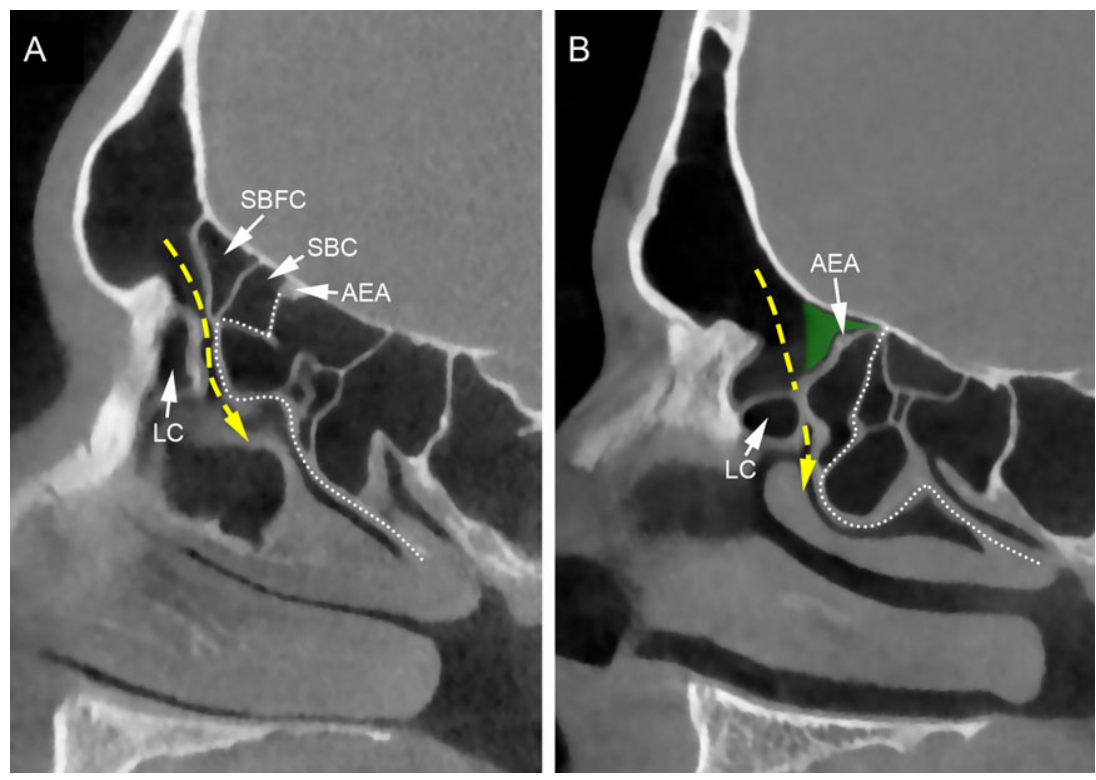

FIGURE 3. The SBFC and suprabullar recess. (A) Sagittal reconstruction showing an SBC and an SBFC. The latter can be defined "frontal" because it extends over the axial plane passing through the floor of the frontal sinus. (B) Sagittal reconstruction showing a suprabullar recess (green area). This space reaches the basal lamella of the middle turbinate (white dotted line) and the AEA. Yellow dashed-arrow = frontal sinus drainage pathway. AEA $=$ anterior ethmoidal artery; $\mathrm{LC}=$ lacrimal cell; $\mathrm{SBC}=$ suprabullar cell; $\mathrm{SBFC}=$ suprabullar frontal cell.

when extended to the surrounding bones. ${ }^{6,7,12}$ The frontal sinus development results from an extramural epithelial migration of the anterior ethmoidal cells, which penetrate the inferior aspect of the frontal bone and guide the pneumatization process between its 2 diploic plates. ${ }^{7}$ This process starts during the 13 th week of intrauterine life and continues up to the age of 20 years. ${ }^{6}$
As supported by the results of the present study, when the upward epithelial migration starts, 3 main scenarios can be observed.

\section{Frontal sinus originating from nasal cells}

When a nasal cell grows toward the frontal bone, it pushes the upper portion of the UP laterally. In this 

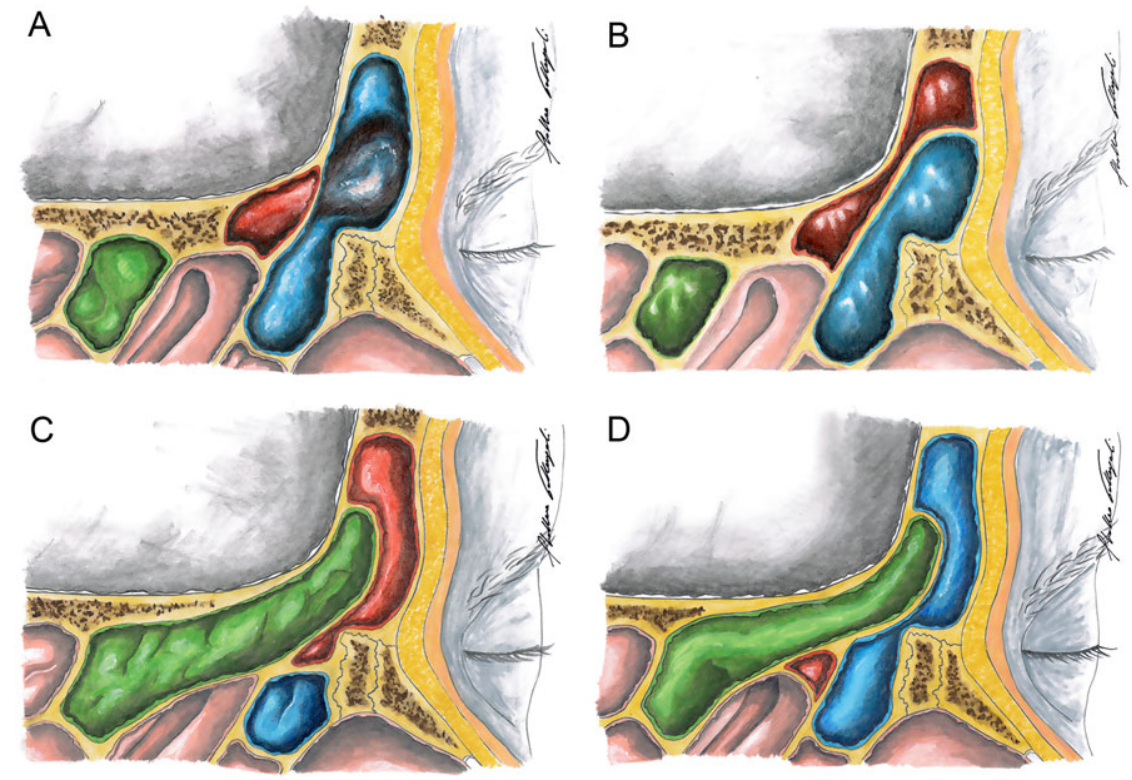

FIGURE 4. Development of frontoethmoidal cells. (A) The supra-agger frontal cell takes form when the frontal sinus arises from the nasal cell and an orbital cell grows toward the frontal bone, thus pushing/dislocating the drainage pathway posteromedially. (B) The frontal septal cell arises from a nasal cell that pushes toward the frontal bone when the frontal sinus originates from the orbital cell, therefore compressing/dislocating the drainage pathway laterally. (C,D) The suprabullar frontal cell arises from a bullar cell that grows toward the frontal bone with the frontal sinus being originated from either the orbital cell (C) or the nasal cell (D); in both the cases, the drainage pathway is pushed and dislocated anteriorly.
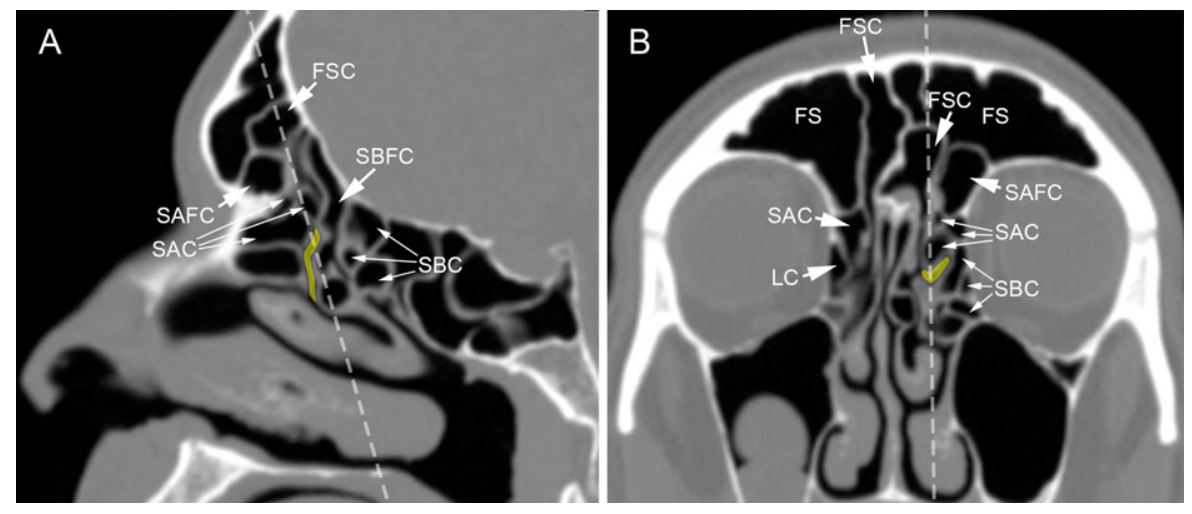

FIGURE 5. Sagittal (A) and paracoronal (B) reconstruction of an extremely compartmentalized frontoethmoidal area. In this complex case, the associations between anatomical variants resulting from the Terracol and Ardouin model are subverted. The $A B C$-acronyms of this case are $m A_{4} F_{L} f$ on the right side and $\mathrm{mA}_{5} \mathrm{FB}_{1}$ on the left side, with 15 air spaces to be marsupialized in a hypothetical surgical procedure. Yellow area $=$ frontal sinus drainage pathway; white dashed-line = plane of section of the paracoronal and sagittal reconstruction. $\mathrm{ABC}=$ agger-bullar classification; $\mathrm{FS}=$ frontal sinus; FSC = frontal septal cell; $L C=$ lacrimal cell; $S A C=$ supra-agger cell; SAFC = supra-agger frontal cell; $S B C=$ suprabullar cell; SBFC = suprabullar frontal cell.

setting, the FSDP is located medially to the UP upper insertions, whereas the orbital and bullar cells give origin to ANC/SAC and SBC, respectively (Fig. 1). Orbital cells protruding into the frontal sinus are defined SAFCs. The association between medial FSDP and the presence of $\mathrm{ANC} / \mathrm{SA}(\mathrm{F}) \mathrm{Cs}$ corroborates this development pathways (Figs. 2-4). Bullar cells pneumatized into the frontal sinus are named SBFCs (Fig. 4). This commonly (80.8\%) happens with medial FSDP. When more than 1 primordial orbital cell is present, both $\mathrm{ANC}$ and $\mathrm{SA}(\mathrm{F}) \mathrm{C}$ can be identified.

\section{Frontal sinus originating from orbital cells}

When the pneumatization of frontal sinus derives from an orbital cell, the upper portion of the UP is pushed medially toward the middle turbinate (Fig. 1). In this configuration, nasal cells can either fuse with the middle nasal meatus (representing its anterosuperior extension) or grow toward the medial portion of the frontal bone extending within the interfrontal sinus septum. In support of this hypothesis, the presence of a FSC originating from the ethmoid was significantly associated with lateral FSDP (Fig. 4). Since orbital primordial cells gave origin to the frontal sinus, they 
cannot give origin to $\mathrm{ANC} / \mathrm{SA}(\mathrm{F}) \mathrm{Cs}$. In fact, the absence of $\mathrm{ANC} / \mathrm{SA}(\mathrm{F}) \mathrm{C}$ was significantly associated with lateral FSDP. If the bullar cell invades the frontal bone, a SBFC will develop. The presence of a SBFC is uncommonly $(19.2 \%)$ associated with a lateral FSDP.

\section{Frontal sinus originating from bullar cells}

When a bullar cell predominates over the other primordial cells, a suprabullar recess develops between the upper portion of the bullar complex and frontal bone (Figs. 1 and 3 ). The presence of both suprabullar recess and SBC has been rarely $(2.6 \%)$ demonstrated; in this case we assume that more than one primordial bullar cell were present and those not forming the frontal sinus gave origin to SBCs. While growing toward the frontal bone, the bullar cell must pass medial or lateral to the suprainfundibular plate. ${ }^{10,11}$ Since the suprabullar recess was mostly associated with a lateral FSDP, we suppose that the bullar cell tends to stay close to the orbit while ascending toward the frontal bone, passing laterally to the suprainfundibular plate.

The knowledge of the 3 developmental patterns we describe can help endoscopic surgeons to understand frontal recess anatomy and variability. Although numerous possible combinations of the anatomical variants can be found, their relationships are mostly constrained by the developmental mechanism of FSDP. When the pattern is recognized at preoperative imaging, the surgeon can easily find the course of the FSDP throughout the frontoethmoidal region and safely marsupialize the surrounding spaces. However, there are cases with a so complex anatomical configuration that cannot fit in the developmental model (Fig. 5). Consequently, Terracol and Ardouin's model is an additional available tool to better understand the frontoethmoidal anatomy that should be integrated with meticulous preoperative images study, surgical-oriented anatomical classification (ABC and IFAC), ${ }^{4,5}$ and navigation-aided dissection. ${ }^{13,14}$

\section{Conclusion}

In the present study, the developmental model proposed by Terracol and Ardouin around 50 years ago has been further validated and readapted in view of several radiologic observations. The knowledge of 3 developmental patterns of the FSDP helps the surgeon to simplify the complexity of the frontoethmoidal region and keep in mind the key relationships among UP, FSDP, and surrounding air spaces. 8

\section{References}

1. Wormald PJ. Surgery of the frontal recess and frontal sinus. Rhinology. 2005;43:82-85.

2. Lee WT, Kuhn FA, Citardi MJ. 3D computed tomographic analysis of frontal recess anatomy in patients graphic analysis of frontal recess anatomy in patients
without frontal sinusitis. Otolaryngol Head Neck without frontal sinusitis.
Surg. 2004;131:164-173.

3. Kuhn F. Chronic frontal sinusitis: the endoscopic frontal recess approach. Oper Tech Otolaryngol Head Neck Surg. 1996;7:222-229.

4. Pianta L, Ferrari M, Schreiber A, et al. Agger-bullar classification $(\mathrm{ABC})$ of the frontal sinus drainage pathway: validation in a preclinical setting. Int Forum A/lergy Rhinol. 2016;6:981-989.

5. Wormald PJ, Hoseman W, Callejas C, et al. The International Frontal Sinus Anatomy Classification (IFAC) and Classification of the Extent of Endoscopic
Frontal Sinus Surgery (EFSS). Int Forum Allergy Rhinol. 2016;6:677-696.

6. Sadler TW. Langman's Medical Embryology. Philadelphia: Wolters Kluwer; 2015.

7. Kountakis SE, Senior BA, Draf W. The Frontal Sinus. New York: Springer; 2005.

8. Terracol J, Ardouin P. [Anatomy of the Nasal Fossae and Associated Cavities]. Paris: Maloine; 1965. French

9. Terrier F, Weber W, Ruefenacht D, et al. Anatomy of the ethmoid: CT, endoscopic, and macroscopic. AJR Am J Roentgenol. 1985;144:493-500.

10. Kim KS, Kim HU, Chung IH, et al. Surgical anatomy of the nasofrontal duct: anatomical and computed tomographic analysis. Laryngoscope. 2001;111: 603-608.
11. Yoon JH, Moon HJ, Kim $\mathrm{CH}$, et al. Endoscopic frontal sinusotomy using the suprainfundibular plate as a key landmark. Laryngoscope. 2002;112 1703-1707.

12. Marquez S, Tessema B, Clement PA, et al. Development of the ethmoid sinus and extramural migration: the anatomical basis of this paranasal sinus. Anat Rec. 2008;291:1535-1553.

13. Yao WC, Bleier BS. Centrifugal frontal sinus dissection technique: addressing anterior and posterior frontoethmoidal air cells. Int Forum Allergy Rhinol. 2015;5:761-763.

14. Oakley GM, Barham HP, Harvey RJ. Utility of imageguidance in frontal sinus surgery. Otolaryngol Clin North Am. 2016;49:975-988. 